\title{
BMI open Antenatal iron/folic acid supplements, but not postnatal care, prevents neonatal deaths in Indonesia: analysis of Indonesia Demographic and Health Surveys 2002/2003-2007 (a retrospective cohort study)
}

\author{
Christiana Rialine Titaley, ${ }^{1}$ Michael John Dibley ${ }^{2}$
}

To cite: Titaley CR, Dibley MJ. Antenatal iron/ folic acid supplements, but not postnatal care, prevents neonatal deaths in Indonesia: analysis of Indonesia Demographic and Health Surveys 2002/2003-2007 (a retrospective cohort study). BMJ Open 2012;2: e001399. doi:10.1136/ bmjopen-2012-001399

- Prepublication history and additional material for this paper are available online. To view these files please visit the journal online (http://dx.doi.org/10.1136/ bmjopen-2012-001399).

CRT and MJD contributed equally to this work.

Received 7 May 2012 Accepted 25 September 2012

This final article is available for use under the terms of the Creative Commons Attribution Non-Commercial 2.0 Licence; see http://bmjopen.bmj.com

${ }^{1}$ Center for Health Research, Universitas Indonesia, Depok, Indonesia

${ }^{2}$ Sydney School of Public Health-University of Sydney, Sydney, Australia

\section{Correspondence to} Dr Christiana Rialine Titaley; christiana_rialine@yahoo.com

\section{ABSTRACT}

Objective: This study aimed to assess the contribution of postnatal services to the risk of neonatal mortality, and the relative contributions of antenatal iron/folic acid supplements and postnatal care in preventing neonatal mortality in Indonesia.

Design: Retrospective cohort study.

Setting and participants: Data used in this study were the 2002-2007 Indonesia Demographic and Health Surveys, nationally representative surveys. The pooled data provided survival information of 26591 most recent live-born infants within the 5-years prior to each interview.

Primary outcomes: Primary outcomes were early neonatal mortality, that is, deaths in the first week, and all neonatal mortality, that is, deaths in the first month of life. Exposures were antenatal iron/folic acid supplementation and postnatal care from days 1 to 7 . Potential

confounders were community, socio-economic status and birthing characteristics and perinatal healthcare. Cox regression was used to assess the association between study factors and neonatal mortality.

Results: Postnatal care services were not associated with newborn survival. Postnatal care on days 1-7 after birth did not reduce neonatal death ( $\mathrm{HR}=1.00,95 \% \mathrm{Cl}$ 0.55 to $1.83, p=1.00$ ) and early postnatal care on day 1 was associated with an increased risk of early neonatal death (HR=1.27, $95 \% \mathrm{Cl} 0.69$ to $2.32, \mathrm{p}=0.44$ ) possibly reflecting referral of ill newborns. Early postnatal care on day 1 was not protective for neonatal deaths on days 2-7 whether provided by doctors (HR $3.61,95 \% \mathrm{Cl} 1.54$ to $8.45, p<0.01$ ), or by midwives or nurses (HR $1.38,95 \%$ $\mathrm{Cl} 0.53$ to $3.57, \mathrm{p}=0.512$ ). In mothers who took iron/folic acid supplements during pregnancy, the risk of early neonatal death was reduced by $51 \%$ (HR=0.49, $95 \% \mathrm{Cl}$ 0.30 to $0.79, p<0.01$ ).

Conclusions: We found no protective effect of postnatal care against neonatal deaths in Indonesia. However, important reductions in the risk of neonatal death were found for women who reported use of antenatal iron/folic acid supplements during pregnancy.

\section{ARTICLE SUMMARY}

Article focus

- Iron/folic acid supplements during pregnancy have been reported to protect against neonatal death.

- Postnatal care services are also claimed to be important to prevent neonatal mortality.

- This study aimed to examine the relative importance of antenatal iron/folic acid supplements and postnatal care services in improving neonatal survival in Indonesia.

Key messages

- Postnatal care did not protect against neonatal and early neonatal deaths after adjusting for the effects of iron/folic acid supplements.

- Iron/folic acid supplements consistently prevented neonatal death and early neonatal deaths (on the first day and after the first day of delivery).

- Programmes aimed at reducing neonatal mortality in Indonesia need to place more emphasis on iron/folic acid supplementation during pregnancy.

- Further research is needed to understand the reasons for the lack of impact of postnatal are on neonatal mortality in Indonesia.

Strengths and limitations of this study

- Data were taken from two nationally representative surveys with large samples and high response rates.

- The survey used a retrospective cohort design in which the mother recalled the health services exposures that occurred prior to the outcome of interest-neonatal death.

- Recall bias was reduced by restricting the analysis to the last birth within 5 years prior to the interview.

- An important limitation was that mothers were not randomised to receive iron/folic acid supplements or postnatal care so there remains a possibility of residual confounding.

- Our analyses were limited by the lack of information about components of the postnatal care delivered. 


\section{INTRODUCTION}

Of 7.7 million child deaths in 2010 worldwide, approximately 3.1 million were neonatal deaths. ${ }^{1}$ Approximately $75 \%$ of neonatal deaths occur in the early neonatal period, or the first 7 days after delivery and $50 \%$ occur in the first $24 \mathrm{~h}^{2}{ }^{2}$ Failure to reduce neonatal deaths might prevent countries from attaining their fourth Millennium Development Goal that is to reduce child mortality by two-third by $2015 .^{2-5}$ Interventions to reduce the number of neonatal deaths are important especially in developing countries. ${ }^{2} 6$

Infants of mothers who receive antenatal care services have a reduced risk of neonatal deaths. ${ }^{7}$ Antenatal services include a pregnancy check-up by health personnel, provision of iron/folic acid supplements, tetanus toxoid vaccination and health education and counselling. In Indonesia, pregnant women are recommended to attend at least four antenatal visits. ${ }^{9}$ The 2007 Indonesia Demographic and Health Survey (IDHS) showed that only $66 \%$ of women had four antenatal visits, lower than the national target of $90 \% .^{10}$ The Ministry of Health also reported a wide discrepancy of antenatal care utilisation across provinces. ${ }^{9}$ DKI Jakarta has the highest $(96 \%)$ and Papua Province the lowest $(38 \%)$ percentage of women attending all visits. ${ }^{9}$

Iron/folic acid supplements reduce the risk of neonatal mortality. ${ }^{11-14}$ In Indonesia, pregnant women should receive 90 tablets of iron/folic acid supplements, which has been used as an indicator of the quality of antenatal care services. ${ }^{9}$ Nonetheless, in 2008 only $48 \%$ of pregnant women received this dose. ${ }^{9}$

Postnatal care services are important in preventing neonatal mortality. ${ }^{15-19}$ Adequate postnatal care is considered vital since most neonatal deaths occur within the first week of life. WHO and UNICEF recommend at least two visits for home births within the first week of the infants' life; whereas for babies delivered in healthcare facilities, the first home visit should be immediately the baby comes home. ${ }^{20}$ In Bangladesh, neonatal deaths were significantly lower among infants who had a postnatal home visit on the first 2 days after delivery. ${ }^{18}$ However, there was no significant reduction of the risk of neonatal death in newborns with their first postnatal visit after the second day of life. In Indonesia, three postnatal home visits have recently been recommended to replace the previous postnatal schedule of two visits with an additional visit in the first week of life. ${ }^{21}$

These findings highlight the need for further examination of the roles of iron/folic acid supplements and postnatal care services in improving neonatal survival. Our aim was to assess the relative contribution of antenatal iron/folic acid supplements and postnatal care services in reducing the risk of neonatal death.

\section{METHODS}

\section{Data sources}

Data of the 2002/2003 and 2007 IDHS were available. ${ }^{22}$ A multistage, stratified, cluster random sampling was used to collect demographic and health information by interviewing ever married women in reproductive age (15-49 years) and ever married men (15-54 years). Three questionnaires used were used. The Household Questionnaire collected information about the economic status of each household. The Women's Questionnaire collected information about sociodemographic characteristics and health-related information, including use of antenatal, delivery and postnatal services and child and maternal deaths. The Men's Questionnaire collected information about men's sociodemographic and health information. The IDHS is designed to produce estimates at the national, provincial and urban/rural level. ${ }^{23}$

In this pooled analysis, survival information from 26591 most recent live-born infants within the 5 years prior to each interview was used, consisting of 12646 infants from the 2002 IDHS and 13945 from the 2007 IDHS. Participation in IDHS has an average response rate of $97 \%$.

\section{Primary outcome and study variables}

The primary outcome was early neonatal death defined as death during the first week of life (days 1-7). All neonatal death was defined as deaths occurring during the first month life (days 1-31).

Iron/folic acid supplement was the reported use of any iron/folic acid during pregnancy. The commonly used formulation in Indonesia is iron $60 \mathrm{mg}$ and folic acid $0.25 \mathrm{mg}$. This variable was based on question of, "For how many days during this pregnancy did you (mother) take the iron?" A mother was classified as using antenatal iron/folic acid supplements if they reported taking iron/folic acid tablets for at least a day during pregnancy, although our analysis did not specifically analyse the number of days mothers took iron supplements.

Postnatal care services received by infants in the first 6 days of life were based on three questions, (1) 'After (NAME) was born, did a health professional or a traditional birth attendant check on his/her health?'; (2) 'How many days or weeks after delivery did the first check take place?' and (3) 'Who checked on (NAME)'s health at that time?' For (3), options were (A) health personnel, that is, general doctor, obstetrician, paediatrician, nurse, midwife (B) traditional birth attendant and (C) other. Three postnatal care variables were constructed: a two-category variable of (1) no postnatal care or postnatal care after day 7 and (2) postnatal care services from days 1 to 7 delivered by any care provider (trained or untrained). Second, a four-category variable consisting of (1) no postnatal care, or postnatal care after day 7 , (2) postnatal care from days 1 to 7 by a doctor/specialist/paediatrician, (3) postnatal care from days 1 to 7 by a nurse/midwife/village midwife and (4) postnatal care from days 1 to 7 by untrained personnel (traditional birth attendants). Third, a three-category variable consisting of (1) no postnatal care/postnatal 
care after day 7 or (2) postnatal care on day 1 and (3) from days 2 to 7 by any type of care provider. During data collection, women were recommended to have at least two postnatal care services, once during days 1 to 7 and once during days 8 to 28 after delivery.

\section{Potential confounding factors}

A framework of factors which might potentially affect child survival in developing countries was adapted for the analysis. ${ }^{24}$ Sixteen potential confounders were classified into two groups: (1) demographic, socio-economic status and birthing characteristics and (2) perinatal healthcare services.

In the first group, 12 variables were region, type of residence (urban/rural), average paternal year of schooling in the cluster, maternal year of education, household wealth index, maternal age at childbirth, child sex, combined birth rank and interval, maternal desire for pregnancy, reported delivery complications (including prolonged labour, excessive vaginal bleeding, fever/foul smelling and convulsions) and combined birth size and duration of pregnancy.

In the second group, two study variables (antenatal iron/folic acid supplements and postnatal care) and use of five perinatal health services (antenatal care, mode of delivery, delivery attendance and place of delivery) were included. Antenatal care services refer any to preventive health services provided by health personnel, such as doctors, midwives or village midwives, during pregnancy. Duration of the recall period between date of childbirth and interview was also included in multivariate models.

Household wealth index used 11 variables from the pooled datasets including source of drinking water, type of toilet, main material of wall, floor, availability of electricity, possession of radio, television, fridge, bicycle, motorcycle and car. Principal component analysis was used to assign weights to create an indicator of household economic status. ${ }^{25}$

A variable of combined birth rank/birth interval was constructed with five-categories, that is, first birth rank infants, second/third birth rank infants with previous birth interval of more than 2 years, second/third rank infants with previous birth interval of less than or equal to 2 years, fourth birth rank infants with previous birth interval of more than 2 years and fourth birth rank infants with previous birth interval of less than or equal to 2 years.

In the analyses, birth size replaced birth weight due to $19 \%$ of infants not weighed at birth. There is a close correlation between mother's assessment of child size and birth weight. ${ }^{26}$

\section{Statistical analysis}

Cox regression was used to examine the association between neonatal mortality and study factors with multivariable analyses to examine associations between early neonatal mortality and study factors after controlling for covariates.
In multivariable analysis, a multistage model using a hierarchical approach was applied. ${ }^{27}$ Using this approach, the association between distal variables with study outcomes can be assessed without improper adjustment by intermediate variables through which the distal variables might affect the outcomes. At the first stage, community, socio-economic status and birthing characteristics, year of IDHS survey and days of recollection period, were entered. Backward elimination was used to remove non-significant factors $(p>0.05)$. Two variables, year of IDHS survey and days of recollection period were selected a priori to be retained in the model to adjust for secular trends.

At the second stage, the use of perinatal healthcare service characteristics including the use of iron/folic acid supplements and postnatal care services were entered with backward elimination to remove nonsignificant factors. Two postnatal care services variables were entered, one at a time, to assess their association with the study outcome. Variables for delivery attendance were retained regardless of significance.

A similar modelling strategy was used to examine predictors of neonatal mortality. In the final models, the same sets of variables were retained for both neonatal and early neonatal deaths. Regression models were also used for early neonatal mortality occurring on the day of birth (day 1) and after day of delivery (days 2-7).

Data were analysed using STATA/MP V.10.00 (Stata Corporation, College Station, Texas, USA). Cox regression models were adjusted for sampling weights and the cluster design.

\section{RESULTS}

There were 26591 live-born singleton infants most recently born to each mother in the prior 5 years, with 219 early neonatal deaths and 290 neonatal deaths. Although neonatal deaths decreased from 115 (IDHS 2002/2003) to 104 (IDHS 2007), the proportion of early neonatal death on the first day of life increased from $47 \%$ to $50 \%$.

Table 1 shows community, socio-economic status and birthing characteristics. Multivariable analyses showed that type of residence (urban/rural), household wealth index and maternal age at childbirth, presence of delivery complications and birth size of the child were significantly associated with early neonatal deaths.

Perinatal healthcare service characteristics are presented in table 2. There was an increased utilisation of antenatal services, trained delivery attendants, institutional deliveries and postnatal services in the last 10 years. However, the use of iron/folic acid supplements decreased from 69\% (IDHS 2002/2003) to 67\% (IDHS 2007).

There was no significant protective effect of postnatal care services regardless of the timing of the service. Table 3 shows no effect of postnatal care by any provider in the first week of life ( $\mathrm{HR}=1.00,95 \%$ CI 0.55 to 1.83 , $\mathrm{p}=1.00$ ). In the univariable analysis the use of postnatal 
Table 1 Frequency distribution, unadjusted and adjusted HRs $(\mathrm{H}(\mathrm{t}))$ of demographic, socio-economic status and birthing characteristics at the community and individual level for early neonatal (days 1-7 after birth) mortality, IDHS $2002 / 2003$ and 2007

\begin{tabular}{|c|c|c|c|c|c|c|c|c|}
\hline \multirow[b]{2}{*}{ Variable } & \multirow[b]{2}{*}{$\mathbf{N}$} & \multirow[b]{2}{*}{ (\%) } & \multicolumn{3}{|c|}{ Unadjusted* } & \multicolumn{3}{|c|}{ Adjusted $^{*}, \dagger$} \\
\hline & & & $\mathbf{H}(\mathrm{t})$ & $(95 \% \mathrm{Cl})$ & p Value & $\mathbf{H ( t )}$ & $(95 \% \mathrm{Cl})$ & p Value \\
\hline \multicolumn{9}{|l|}{ Year of survey } \\
\hline IDHS 2002/2003 & 12646 & $(47.6)$ & 1.00 & & & 1.00 & & \\
\hline IDHS 2007 & 13945 & (52.4) & 0.88 & (0.56 to 1.39$)$ & 0.59 & 0.89 & (0.57 to 1.39$)$ & 0.60 \\
\hline \multicolumn{9}{|l|}{ Community level factors } \\
\hline \multicolumn{9}{|l|}{ Region } \\
\hline Java-Bali region & 15486 & (58.2) & 1.00 & & & & & \\
\hline Sumatera & 5615 & $(21.1)$ & 1.06 & (0.63 to 1.77$)$ & 0.83 & & & \\
\hline Eastern Indonesia & 5490 & (20.6) & 1.09 & (0.70 to 1.71$)$ & 0.70 & & & \\
\hline \multicolumn{9}{|l|}{ Type of residence } \\
\hline Urban & 11776 & (44.3) & 1.00 & & & 1.00 & & \\
\hline Rural & 14815 & $(55.7)$ & 0.79 & (0.50 to 1.24$)$ & 0.30 & 0.57 & (0.33 to 0.97$)$ & 0.04 \\
\hline $\begin{array}{l}\text { Average paternal } \\
\text { years of schooling }\end{array}$ & \multicolumn{2}{|c|}{ Mean \pm SE $=8.43 \pm 0.07$} & 0.98 & (0.90 to 1.06$)$ & 0.60 & & & \\
\hline \multicolumn{9}{|c|}{ Household and individual level factors } \\
\hline \multicolumn{9}{|c|}{ Maternal marital status } \\
\hline Currently married & 25953 & (97.6) & 1.00 & & & & & \\
\hline Formerly married & 638 & $(2.4)$ & 1.68 & $(0.50$ to 5.70$)$ & 0.40 & & & \\
\hline $\begin{array}{l}\text { Maternal year of } \\
\text { education }\end{array}$ & Mean \pm & $8.01 \pm 0.07$ & 0.98 & (0.93 to 1.03$)$ & 0.43 & & & \\
\hline $\begin{array}{l}\text { Household wealth } \\
\text { index }\end{array}$ & Mean \pm & $0.23 \pm 0.04$ & 0.90 & (0.81 to 0.99$)$ & 0.03 & 0.85 & $(0.75$ to 0.96$)$ & 0.01 \\
\hline $\begin{array}{l}\text { Maternal age at } \\
\text { childbirth }\end{array}$ & Mean \pm & $27.19 \pm 0.07$ & 1.05 & (1.01 to 1.09$)$ & 0.02 & 1.05 & (1.01 to 1.09$)$ & 0.01 \\
\hline \multicolumn{9}{|l|}{ Child sex } \\
\hline Female & 12764 & $(48.0)$ & 1.00 & & & & & \\
\hline Male & 13827 & $(52.0)$ & 1.42 & (0.89 to 2.29$)$ & 0.15 & 1.53 & (0.93 to 2.51$)$ & 0.09 \\
\hline \multicolumn{9}{|c|}{ Birth rank and birth interval } \\
\hline First rank & 10751 & $(40.4)$ & 1.00 & & & & & \\
\hline $\begin{array}{l}\text { Second/third rank, } \\
\text { interval >2 years }\end{array}$ & 9139 & $(34.4)$ & 1.14 & (0.62 to 2.10$)$ & 0.66 & & & \\
\hline $\begin{array}{l}\text { Second/third rank, } \\
\text { interval <2 years }\end{array}$ & 1570 & $(5.9)$ & 1.14 & (0.44 to 2.93$)$ & 0.79 & & & \\
\hline $\begin{array}{l}\geq 4 \text { th rank, interval } \\
>2 \text { years }\end{array}$ & 4443 & $(16.7)$ & 1.88 & (1.02 to 3.47$)$ & 0.04 & & & \\
\hline $\begin{array}{l}\geq 4 \text { th rank, interval } \\
\leq 2 \text { years }\end{array}$ & 687 & $(2.6)$ & 1.95 & (0.88 to 4.32$)$ & 0.10 & & & \\
\hline \multicolumn{9}{|l|}{ Desire for pregnancy } \\
\hline Wanted then & 21560 & (81.1) & 1.00 & & & & & \\
\hline Wanted later & 2907 & (10.9) & 1.15 & (0.55 to 2.42 ) & 0.71 & & & \\
\hline Wanted no more & 2044 & $(7.7)$ & 1.53 & (0.67 to 3.51$)$ & 0.31 & & & \\
\hline \multicolumn{9}{|l|}{ Delivery complications } \\
\hline No & 15253 & (57.4) & 1.00 & & & 1.00 & & \\
\hline Yes & 11007 & $(41.4)$ & 1.68 & (1.04 to 2.72$)$ & 0.03 & 1.73 & (1.08 to 2.77 ) & 0.02 \\
\hline \multicolumn{9}{|l|}{ Birth size } \\
\hline Average-sized & 13912 & (52.3) & 1.00 & & & 1.00 & & \\
\hline $\begin{array}{l}\text { Smaller than } \\
\text { average }\end{array}$ & 3552 & $(13.4)$ & 4.34 & (2.66 to 7.09 ) & $<0.001$ & 4.33 & (2.64 to 7.12 ) & $<0.001$ \\
\hline $\begin{array}{l}\text { Larger than } \\
\text { average }\end{array}$ & 8206 & $(30.9)$ & 0.85 & (0.43 to 1.69$)$ & 0.64 & 0.80 & (0.39 to 1.63$)$ & 0.54 \\
\hline
\end{tabular}

All figures were weighted for the sampling probability.

*Data on 3307 cases were missing and they were excluded from the analysis.

†Model also adjusted for recall period.

IDHS, Indonesia Demographic and Health Survey. 
Table 2 Frequency distribution for perinatal healthcare service characteristics, IDHS 2002/2003 and 2007

\begin{tabular}{|c|c|c|c|c|}
\hline \multirow[b]{2}{*}{ Variable } & \multirow[b]{2}{*}{$\mathbf{N}$} & \multirow[b]{2}{*}{$(\%)$} & \multicolumn{2}{|c|}{ Year of IDHS } \\
\hline & & & $2002 / 2003$ & 2007 \\
\hline \multicolumn{5}{|l|}{ Use of antenatal services } \\
\hline No & 1914 & $(7.2)$ & 8.0 & 6.5 \\
\hline Yes & 24483 & (92.1) & 91.2 & 92.8 \\
\hline \multicolumn{5}{|l|}{ Mode of delivery } \\
\hline Non-caesarean section & 25007 & $(94.0)$ & 96.0 & 92.3 \\
\hline Caesarean section & 1509 & $(5.7)$ & 4.0 & 7.2 \\
\hline \multicolumn{5}{|l|}{ Delivery attendance } \\
\hline Untrained delivery attendants & 7712 & $(29.0)$ & 32.5 & 25.8 \\
\hline Trained delivery attendants & 18847 & (70.9) & 67.3 & 74.2 \\
\hline \multicolumn{5}{|l|}{ Place of delivery } \\
\hline Non-health facility & 14674 & $(55.2)$ & 59.0 & 51.8 \\
\hline Health facility & 11839 & (44.5) & 40.8 & 47.9 \\
\hline \multicolumn{5}{|l|}{ Use of iron/folic acid supplements } \\
\hline Never/do not know & 7482 & $(28.1)$ & 27.7 & 28.5 \\
\hline Any iron/folic acid supplements & 17958 & (67.5) & 68.7 & 66.5 \\
\hline \multicolumn{5}{|l|}{ PNC on the first day of life by ANY providers } \\
\hline No PNC or 8+ PNC & 5349 & $(20.1)$ & 20.0 & 20.3 \\
\hline Days $1-7$ PNC by any provider & 21225 & (79.8) & 80.0 & 79.7 \\
\hline \multicolumn{5}{|l|}{ PNC in the first week of life by ANY providers } \\
\hline No PNC or 8+ PNC & 5349 & $(20.1)$ & 20.0 & 20.3 \\
\hline PNC 1-7 by doctors/OBGYN/ paediatrician & 2858 & $(10.8)$ & 10.1 & 11.3 \\
\hline PNC $1-7$ by nurse/midwife/village midwife & 13941 & (52.4) & 51.0 & 53.7 \\
\hline PNC $1-7$ by traditional birth attendant & 4426 & (16.6) & 18.9 & 14.6 \\
\hline \multicolumn{5}{|l|}{ Day in the first week of life by ANY providers(2) } \\
\hline No PNC or 8+ PNC & 5786 & $(21.8)$ & 23.4 & 20.3 \\
\hline Day 1 PNC & 13000 & (48.9) & 43.5 & 53.8 \\
\hline Days 1-7 PNC & 7791 & (29.3) & 33.0 & 25.9 \\
\hline
\end{tabular}

care services showed protection for early neonatal deaths, although not significant $(\mathrm{HR}=0.79,95 \%$ CI 0.44 to $1.43, \mathrm{p}=0.44)$; however, when use of iron/folic acid supplements was included, this effect disappeared. Similar findings were observed for the effect of postnatal care services according to the timing of the care (table 3, model 2). There was an increased HR for infants who received care by any provider on the day of delivery $(\mathrm{HR}=1.27,95 \%$ CI 0.69 to 2.32, $\mathrm{p}=0.44)$, although not significant. There was a change in the direction of early postnatal care services provided after birth (day 1) on early neonatal deaths when use of iron/folic acid supplements was included in the model.

When antenatal care service was added back into the final model, the result remained essentially the same with use of iron/folic acid being protective of neonatal deaths $(\mathrm{HR}=0.51,95 \%$ CI 0.31 to $0.82, \mathrm{p}=0.01)$ and use of postnatal care having no effect on neonatal deaths $(\mathrm{HR}=1.00,95 \%$ CI 0.55 to $1.83, \mathrm{p}=1.00)$.

Using the same variables, analyses of perinatal care services for all neonatal mortality (1-31 days) showed similar findings (table 4). An increased HR ( $\mathrm{HR}=1.21$, $95 \%$ CI 0.70 to $2.09, \mathrm{p}=0.49$ ) was associated with infants who received postnatal care by any provider in the first week of life (model 1). The HR of postnatal care services also changed direction from being protective $(\mathrm{HR}=0.98,95 \%$ CI 0.58 to $1.65, \mathrm{p}=0.93)$ against neonatal mortality in the univariable analyses, to an increased risk after adjusting for iron/folic acid supplements. When the effect of early postnatal care services (on day 1) was examined, there was no significant protection of postnatal care in univariable ( $\mathrm{HR}=1.09,95 \%$ CI 0.63 to $1.87, \mathrm{p}=0.76)$ or multivariable analysis $(\mathrm{HR}=1.43,95 \%$ CI 0.83 to $2.47, \mathrm{p}=0.20)$ after adjusting for iron/folic acid supplements (model 2). When antenatal care service was added back into the final model for all neonatal deaths, the results did not change (data not shown).

In contrast, we found the benefit of iron/folic acid supplements to be consistently present across all models. Antenatal use of these supplements significantly reduced the risk of early neonatal death by 49 $51 \%$ (table 3) and all neonatal deaths by $48-49 \%$ (table 4).

Figure 1 presents the results of the multivariable analyses for early neonatal deaths according to the provider of postnatal care services. For all providers, postnatal care in the first week of life did not protect infants from neonatal death. There was a tendency for infants who received care from trained providers to have a slightly higher risk and 
Table 3 Unadjusted and adjusted $\mathrm{HRs}(\mathrm{H}(\mathrm{t}))$ of perinatal healthcare service characteristics for early neonatal (days 1-7 after birth) mortality, IDHS 2002/2003 and 2007

\begin{tabular}{|c|c|c|c|c|c|c|c|c|c|}
\hline \multirow[b]{2}{*}{ Variable } & \multicolumn{3}{|c|}{ Unadjusted } & \multicolumn{3}{|c|}{ Adjusted (model 1) ${ }^{\star} \dagger$} & \multicolumn{3}{|c|}{ Adjusted (model 2)* $¥$} \\
\hline & $H(t)$ & $(95 \% \mathrm{Cl})$ & $\begin{array}{l}\mathbf{p} \\
\text { Value }\end{array}$ & $H(t)$ & $(95 \% \mathrm{Cl})$ & $\begin{array}{l}\text { p } \\
\text { Value }\end{array}$ & $H(t)$ & $(95 \% \mathrm{Cl})$ & $\begin{array}{l}\mathbf{p} \\
\text { Value }\end{array}$ \\
\hline \multicolumn{10}{|l|}{ Use of antenatal services } \\
\hline No & 1.00 & & & & & & & & \\
\hline Yes & 0.55 & (0.27 to 1.13$)$ & 0.10 & & & & & & \\
\hline \multicolumn{10}{|l|}{ Mode of delivery } \\
\hline Non-caesarean section & 1.00 & & & & & & & & \\
\hline Caesarean section & 1.75 & (0.76 to 4.05$)$ & 0.19 & & & & & & \\
\hline \multicolumn{10}{|l|}{ Delivery attendants } \\
\hline Untrained delivery attendants & 1.00 & & & 1.00 & & & & & \\
\hline Trained delivery attendants & 1.12 & (0.68 to 1.86$)$ & 0.66 & 1.51 & (0.77 to 2.94$)$ & 0.23 & 1.46 & (0.75 to 2.83 ) & 0.27 \\
\hline \multicolumn{10}{|l|}{ Place of delivery } \\
\hline Non-health facility & 1.00 & & & & & & & & \\
\hline Health facility & 1.03 & (0.64 to 1.65$)$ & 0.91 & & & & & & \\
\hline \multicolumn{10}{|c|}{ Use of iron/folic acid (IFA) supplements } \\
\hline Never/do not know & 1.00 & & & 1.00 & & & 1.00 & & \\
\hline Any IFA & 0.48 & (0.30 to 0.79$)$ & $<0.01$ & 0.51 & (0.31 to 0.82$)$ & 0.01 & 0.49 & $(0.30$ to 0.79$)$ & $<0.01$ \\
\hline \multicolumn{10}{|c|}{ Days $1-7$ PNC by any care providers } \\
\hline No PNC or day 8+ PNC & 1.00 & & & 1.00 & & & & & \\
\hline $\begin{array}{l}\text { Days } 1-7 \text { PNC by any } \\
\text { provider }\end{array}$ & 0.79 & (0.44 to 1.43$)$ & 0.44 & 1.00 & (0.55 to 1.83$)$ & 1.00 & & & \\
\hline \multicolumn{10}{|l|}{ Day 1 PNC by any care providers } \\
\hline No PNC or 8+ PNC & 1.00 & & & & & & 1.00 & & \\
\hline Day 1 PNC by any provider & 0.96 & (0.52 to 1.76$)$ & 0.90 & & & & 1.27 & (0.69 to 2.32$)$ & 0.44 \\
\hline $\begin{array}{l}\text { Days } 2-7 \text { PNC by any } \\
\text { provider }\end{array}$ & 0.76 & (0.37 to 1.56$)$ & 0.45 & & & & 0.91 & (0.44 to 1.90$)$ & 0.80 \\
\hline \multicolumn{10}{|c|}{$\begin{array}{l}\text { All results are weighted for sampling probability. *Data on } 3307 \text { cases were missing and they were excluded from the analysis. } \\
\text { †Model } 1 \text { examined the effects of days } 1-7 \text { PNC by any care providers and adjusted for duration of recall period at interview, year of survey, } \\
\text { type of residence, household wealth index, maternal age at childbirth, presence of complication at delivery, sex of the child and child size at } \\
\text { birth based on mother's subjective assessment. } \\
\text { ¥Model } 2 \text { examined the effects of day } 1 \text { PNC by any care providers and adjusted for duration of recall period at interview, year of survey, type } \\
\text { of residence, household wealth index, maternal age at childbirth, presence of complication at delivery, sex of the child and child size at birth } \\
\text { based on mother's subjective assessment. } \\
\text { IDHS, Indonesia Demographic and Health Survey; PNC, postnatal care. }\end{array}$} \\
\hline
\end{tabular}

untrained providers a slightly lower risk of neonatal death, perhaps reflecting a referral of ill newborns.

There was a significant interaction between postnatal care services and urban/rural residence. In urban areas there was no significant protective effect of postnatal care on early neonatal deaths among infants receiving postnatal care within the first week of life either by medical doctors $(\mathrm{HR}=0.94,95 \%$ CI 0.31 to $2.85, \mathrm{p}=0.92)$, nurse or midwives $(\mathrm{HR}=0.8895 \%$ CI 0.28 to 2.73 , $\mathrm{p}=0.83)$ or traditional birth attendants $(\mathrm{HR}=0.94,95 \%$ CI 0.24 to $3.64, p=0.93)$. However, in rural areas, the risk for early neonatal deaths increased significantly in infants who received postnatal care from medical doctors $(\mathrm{HR}=5.44,95 \%$ CI 1.84 to $16.11, \mathrm{p}<0.01)$ but infants who received care from traditional birth attendants had a lower risk $(\mathrm{HR}=0.38,95 \%$ CI 0.16 to 0.90 , $\mathrm{p}=0.03)$. There was no significant interaction between the place of delivery or delivery complications and postnatal care services.

Figure 2 shows neonatal deaths on the day of delivery. There was no protection for day 1 death from postnatal care provided by midwives/nurse or traditional birth attendants. There was a significantly increased risk in infants who received postnatal care services from medical doctors $(\mathrm{HR}=3.61,95 \%$ CI 1.54 to $8.45, \mathrm{p}<0.01)$.

Figure 3 shows the effect of postnatal care services on the day of delivery on the risk of neonatal deaths days 2-7. There was no protective effect of postnatal care services provided immediately after delivery. An increased HR was associated with postnatal care services on the day of delivery, although borderline significant $(\mathrm{HR}=2.05,95 \%$ CI 0.95 to $4.42, \mathrm{p}=0.07)$. However, there was an increased risk when postnatal care was first delivered beyond the first day after delivery $(\mathrm{HR}=2.47,95 \%$ CI 1.06 to $5.78, \mathrm{p}=0.04)$.

\section{DISCUSSION}

\section{Main findings}

Using data from two nationally representative surveys, we found no protective effect of postnatal care services for newborn survival after adjusting for the effects of 
Table 4 Unadjusted and adjusted HRs $(\mathrm{H}(\mathrm{t}))$ of perinatal healthcare service characteristics for all neonatal (1-31 days) mortality, IDHS 2002/2003 and 2007

\begin{tabular}{|c|c|c|c|c|c|c|c|c|c|}
\hline \multirow[b]{2}{*}{ Variable } & \multicolumn{3}{|c|}{ Unadjusted } & \multicolumn{3}{|c|}{ Adjusted† (Model 1) } & \multicolumn{3}{|c|}{ Adjusted $^{\star} ¥$ (Model 2$)$} \\
\hline & $\mathbf{H}(\mathrm{t})$ & $(95 \% \mathrm{Cl})$ & p Value & $\mathbf{H}(\mathrm{t})$ & $(95 \% \mathrm{Cl})$ & p Value & $\mathbf{H}(\mathbf{t})$ & $(95 \% \mathrm{Cl})$ & p Value \\
\hline \multicolumn{10}{|l|}{ Use of antenatal services } \\
\hline No & 1.00 & & & & & & & & \\
\hline Yes & 0.40 & (0.21 to 0.77$)$ & 0.01 & & & & & & \\
\hline \multicolumn{10}{|l|}{ Mode of delivery } \\
\hline Non-caesarean section & 1.00 & & & & & & & & \\
\hline Caesarean section & 2.06 & (0.94 to 4.53$)$ & 0.07 & & & & & & \\
\hline \multicolumn{10}{|l|}{ Delivery attendance } \\
\hline $\begin{array}{l}\text { Untrained delivery } \\
\text { attendants }\end{array}$ & 1.00 & & & 1.00 & & & 1.00 & & \\
\hline Trained delivery attendants & 0.92 & (0.58 to 1.44$)$ & 0.70 & 1.05 & (0.57 to 1.93$)$ & 0.88 & 1.03 & (0.57 to 1.87$)$ & 0.93 \\
\hline \multicolumn{10}{|c|}{ Place of delivery } \\
\hline Non-health facility & 1.00 & & & & & & & & \\
\hline Health facility & 0.97 & (0.64 to 1.48$)$ & 0.89 & & & & & & \\
\hline \multicolumn{10}{|c|}{ Use of iron/folic acid supplements } \\
\hline Never/do not know & 1.00 & & & 1.00 & & & 1.00 & & \\
\hline Any iron/folic acid & 0.51 & (0.33 to 0.79$)$ & $<0.01$ & 0.52 & (0.33 to 0.82$)$ & 0.01 & 0.51 & (0.32 to 0.81$)$ & 0.01 \\
\hline \multicolumn{10}{|c|}{ Days 1-7 PNC by any care providers } \\
\hline No PNC or day $7+$ PNC & 1.00 & & & 1.00 & & & & & \\
\hline $\begin{array}{l}\text { Days } 1-7 \text { PNC by any } \\
\text { provider }\end{array}$ & 0.98 & (0.58 to 1.65$)$ & 0.93 & 1.21 & (0.70 to 2.09$)$ & 0.49 & & & \\
\hline \multicolumn{10}{|l|}{ Day 1 PNC by any care providers } \\
\hline No PNC or $8+$ PNC & 1.00 & & & & & & 1.00 & & \\
\hline Day 1 PNC by any provider & 1.09 & (0.63 to 1.87$)$ & 0.76 & & & & 1.43 & (0.83 to 2.47$)$ & 0.20 \\
\hline $\begin{array}{l}\text { Days } 2-7 \text { PNC by any } \\
\text { provider }\end{array}$ & 1.06 & (0.56 to 1.97$)$ & 0.87 & & & & 1.22 & (0.64 to 2.34$)$ & 0.54 \\
\hline \multicolumn{10}{|c|}{$\begin{array}{l}\text { All results are weighted for sampling probability. } \\
\text { *Data on } 3307 \text { cases were missing and they were excluded from the analysis. } \\
\text { †Model } 1 \text { examined the effects of days } 1-7 \text { PNC by any care providers and adjusted for duration of recall period at interview, year of survey, } \\
\text { type of residence, household wealth index, maternal age at childbirth, sex of the child, delivery complications, child size at birth, delivery } \\
\text { attendants and use of iron/folic acid supplements. } \\
\text { †Model } 2 \text { examined the effects of day } 1 \text { PNC by any care providers and adjusted for duration of recall period at interview, year of survey, type } \\
\text { of residence, household wealth index, maternal age at childbirth, sex of the child, delivery complications, child size at birth, delivery attendants } \\
\text { and use of iron/folic acid supplements. } \\
\text { IDHS, Indonesia Demographic and Health Survey. }\end{array}$} \\
\hline
\end{tabular}

iron/folic acid supplements. An increased risk of early neonatal death on the day of delivery was associated with postnatal care services from medical doctors, which might be related to referral bias. The strongest evidence of a lack of protective effect of postnatal care for neonatal deaths was our failure to show any protective effects for postnatal care delivered on the first day of life, for subsequent neonatal deaths in both early and overall neonatal periods. In contrast, we confirmed the protective role of iron/folic acid supplements during pregnancy. The risk of early neonatal death was reduced by $51 \%$ when mothers took iron/folic acid during pregnancy and this result remained unchanged when use of antenatal care was included in the model. Iron/folic acid supplements were consistently found to prevent early neonatal deaths on the first day (60\% reduction) and after the first day of delivery ( $46 \%$ reduction). Similar findings were observed for all neonatal deaths, with a $49 \%$ reduction in risk of death with iron/folic acid supplementation.

\section{Strengths and limitations}

Data were from two nationally representative surveys with large samples and high response rates. ${ }^{10} 28$ To increase validity, we used multivariable analyses to adjust for potential risk factors at the individual, household, and community levels, and adjusted for perinatal healthcare services, such as type of delivery attendant. The restriction of the analysis to the last birth within 5 years should have reduced recall errors ${ }^{29}{ }^{30}$ and we further adjusted for time between the recalled birth and the interview in all models.

Despite taking an account of many confounders, an important limitation was that mothers were not randomised to receive iron/folic acid supplements or postnatal care so there remains a possibility of residual confounding. Furthermore, our analyses were limited by the lack of information about components of the postnatal care delivered. Only surviving mothers were interviewed and this might have led to an underestimate of neonatal deaths, considering the association between 


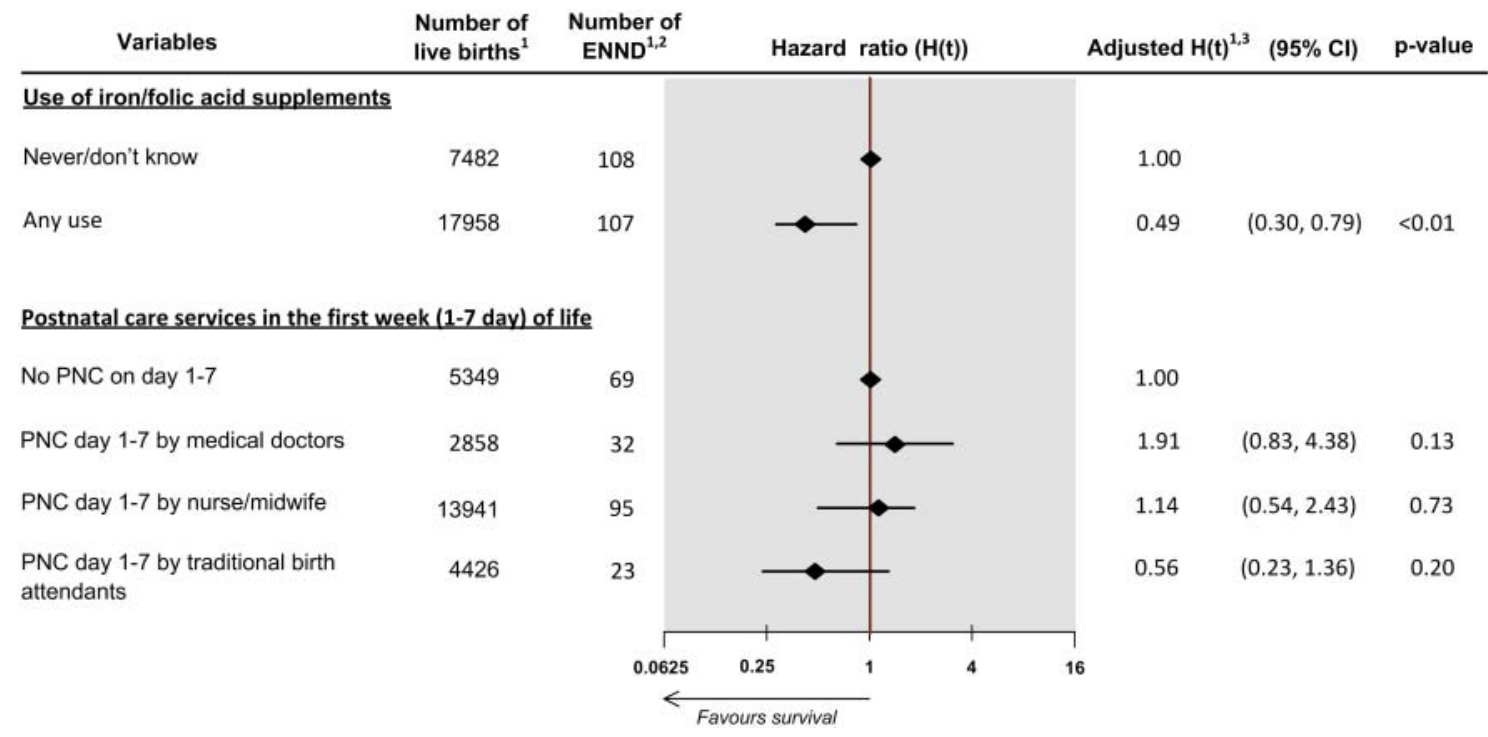

Figure 1 The association between iron/folic acid supplementation and postnatal care services with early neonatal mortality, Indonesia Demographic and Health Survey 2002/2003 and 2007.

Note: ${ }^{1}$ Weighted for the sampling probability, ${ }^{2}$ ENND = early neonatal death, ${ }^{3}$ model obtained by using Cox Proportional Hazards regression analysis and adjusted for duration of recall period at interview, year of survey, type of residence, household wealth index, maternal age at childbirth, presence of complication at delivery, sex of the child and child size at birth based on mother's subjective assessment. All values are weighted for the sampling probability. Data on 3307 cases were missing and they were excluded from the analysis. See Web online supplementary table $\mathrm{S} 1$ for details of this model.

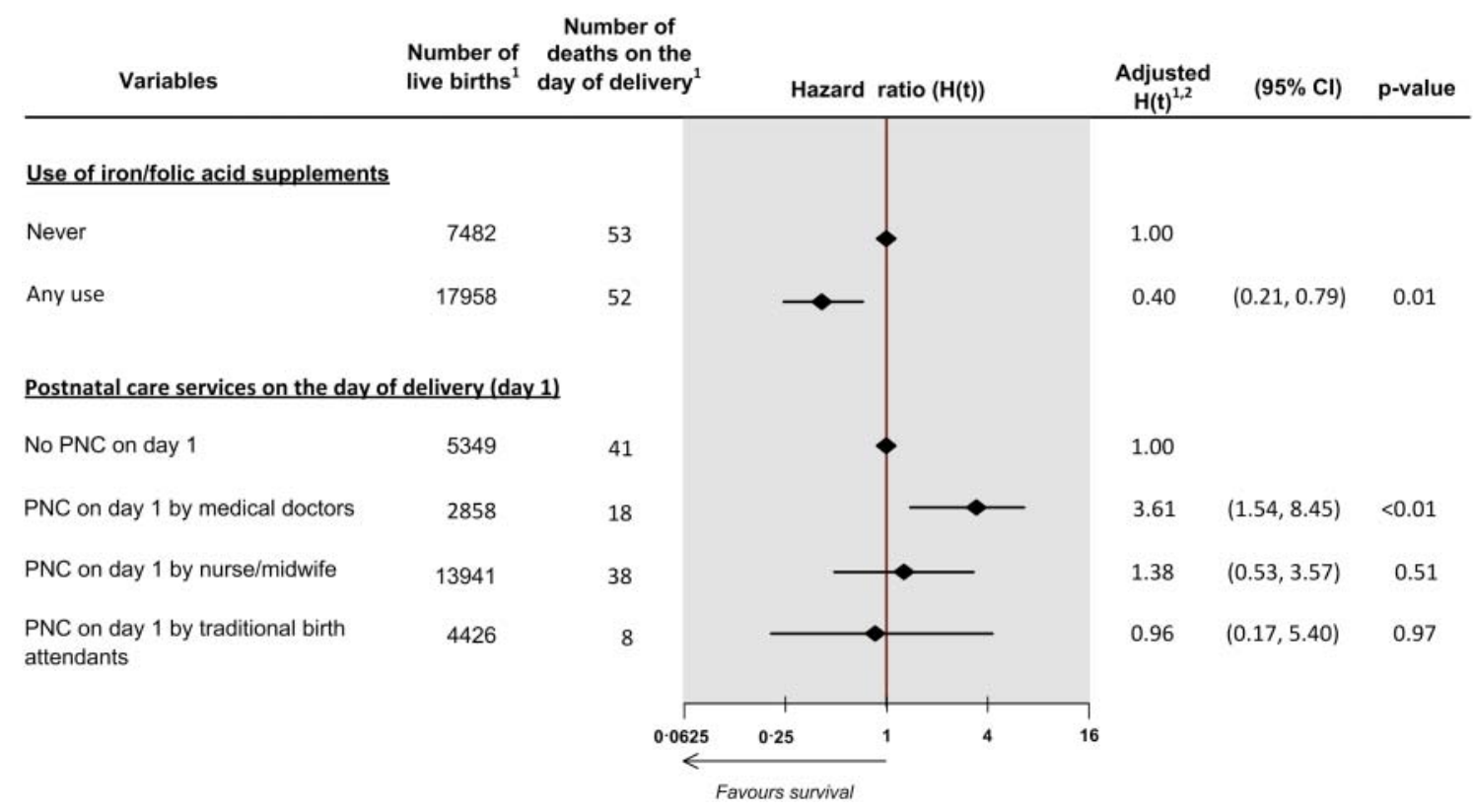

Figure 2 The association between iron/folic acid supplementation and postnatal care services with early neonatal deaths occurring on the day of delivery (day 1), Indonesia Demographic and Health Survey 2002/2003 and 2007.

Note: ${ }^{1}$ Weighted for the sampling probability, ${ }^{2}$ ENND=early neonatal death, ${ }^{3}$ Model obtained by using Cox Proportional Hazards regression analysis and adjusted for duration of recall period at interview, year of survey, type of residence, household wealth index, maternal age at childbirth, presence of complication at delivery, sex of the child and child size at birth based on the mother's subjective assessment. All values are weighted for the sampling probability. Data on 3307 cases were missing and they were excluded from the analysis. See Web online supplementary table $\mathrm{S} 2$ for details of this model. 


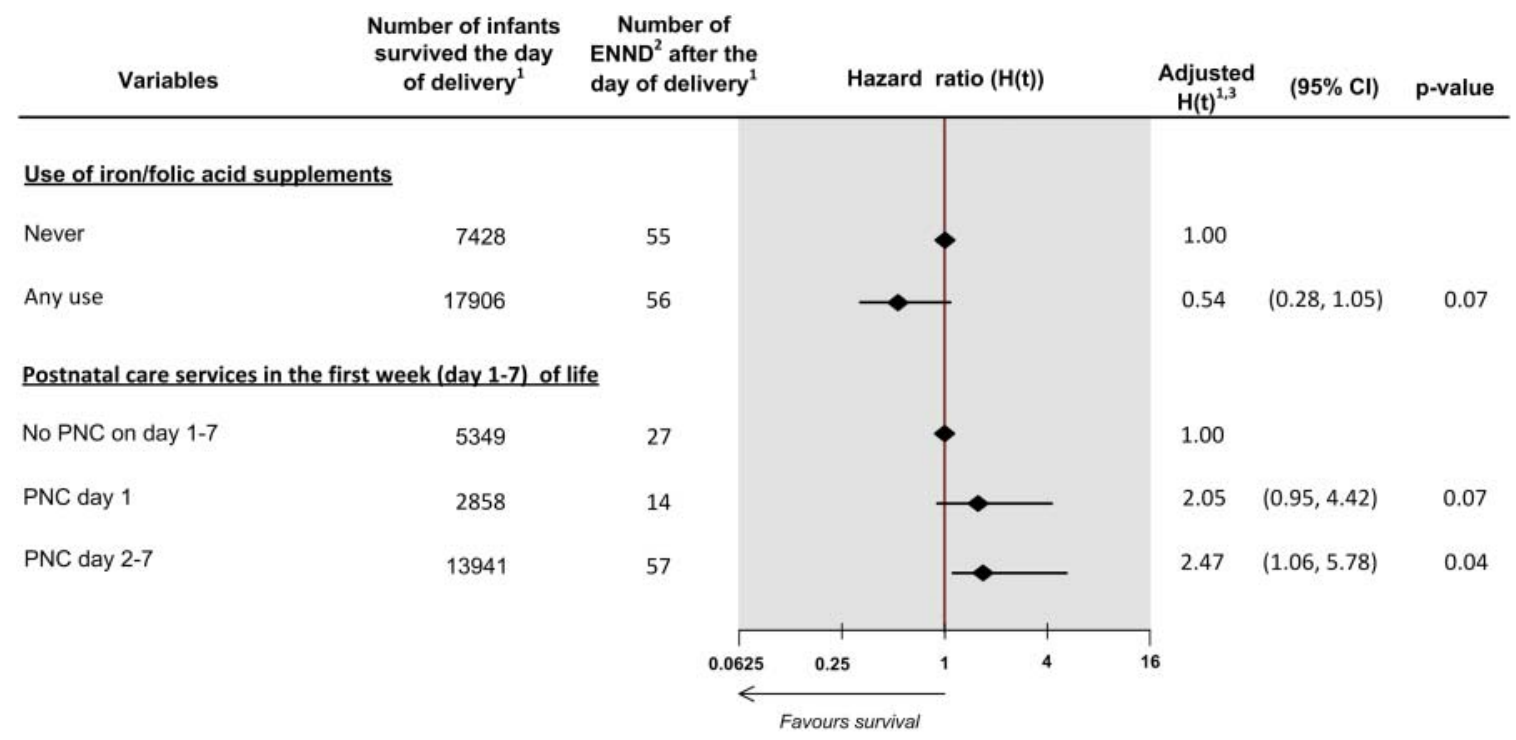

Figure 3 The association between iron/folic acid supplementation and postnatal care services with early neonatal deaths occurring after the day of delivery (days 2-7), Indonesia Demographic and Health Survey 2002/2003 and 2007.

Note: ${ }^{1}$ Weighted for the sampling probability, ${ }^{2}$ ENND=early neonatal death, ${ }^{3}$ Model obtained by using Cox Proportional Hazards regression analysis and adjusted for duration of recall period at interview, year of survey, type of residence, household wealth index, maternal age at childbirth, presence of complication at delivery, sex of the child and child size at birth based on the mother's subjective assessment. All values are weighted for the sampling probability. Data on 3290 cases were missing and they were excluded from the analysis.

maternal and neonatal mortality. ${ }^{31}$ The selection of confounders was also determined by the availability of information in the datasets. The cross-sectional data collected implies concurrent measurement of exposure and outcome, which would limit interpretation of causality. All information used in this analysis was based on the mothers' recollection and therefore might be subject to recall and misclassification bias. However, this may occur equally to all information provided about perinatal health services. The effect of this misclassification bias, if present, would most likely have led to an apparently reduced effect measure for both iron/folic acid and postnatal care services on neonatal mortality. Moreover, the use of iron/folic acid was recalled by the mother as an exposure antecedent to neonatal death and thus has an appropriate timing element. Similarly, the postnatal care on the first day of life was antecedent to neonatal deaths on days 2-7. The wide-ranging interview with the mother that covered many different topics is likely to have reduced differential recall by mothers with and without neonatal deaths.

\section{Comparison with other studies}

After adjusting for significant predictors including antenatal care services and iron/folic acid supplements, we did not find any protective effect of early provision of postnatal care services on neonatal deaths. The change of direction in the effect of postnatal care services provided by nurses and midwives after adjustment for iron/folic acid supplements signifies a stronger effect of the supplements which confounded the effects of postnatal care services on neonatal survival. This indicates the need to adjust for use of antenatal iron/folic acid when evaluating the impact of interventions to reduce neonatal deaths.

A key part of the evidence used by WHO/UNICEF ${ }^{32}$ to recommend wide use of postnatal care to reduce neonatal deaths was a cluster-randomised trial in Sylhet District, Bangladesh that reported a reduction in neonatal mortality by $34 \%$ with home care, in which community health workers made antenatal and postnatal home visits. ${ }^{16}$ However, in Mirzapur, Bangladesh, a cluster-randomised trial using the same home-based postnatal care intervention, evaluated with the same methodologies, failed to find any improvement in neonatal mortality compared to usual programs. ${ }^{33}$ This difference in the impact of postnatal care home visits might be explained by a larger increase in the percentage of pregnant women using iron/folic acid supplements in the intervention group in the Sylhet trial $(43 \%$ at baseline to $84 \%$ at endline) compared to the Mirzapur trial (from $48 \%$ to $56 \%$ ). Data from the Sylhet trial have been used to assess the effect of the timing of the first postnatal care home visit by trained community health workers. ${ }^{18}$ This study used data from health workers' records of the home care treatment arm. Although $97 \%$ of the women in this group received at least one antenatal home visit, ${ }^{18}$ the endline survey ${ }^{16}$ for the trial revealed $84 \%$ of the women in the home care treatment arm reported any use of iron/folic acid supplements but the number of supplements used was 
not reported. In the analyses that found home postnatal care within the first two days of life significantly reduced neonatal mortality there was no adjustment made for the use of antenatal iron/folic acid. It is possible that earlier postnatal care was associated with greater use of antenatal iron/folic acid and could have confounded these results.

In Nepal, ${ }^{34}$ a community-based participatory intervention to increase the use of perinatal care services and 'consultations for difficulties in pregnancy and the newborn period' also showed a reduction in the neonatal death rate in intervention clusters; however as in Bangladesh, there was an increased proportion of women taking iron/folic supplement in the intervention group that might have accounted for the reduced mortality. Two other trials of community-based interventions to increase the use of perinatal health services including postnatal care, reported significant reductions in newborn deaths as well as demonstrated increased uptake of antenatal care, although they did not specifically report use of iron/folic acid supplements. ${ }^{17} 19$ Finally a classic quasi-experiment in India ${ }^{15}$ in which female village health workers were trained to detect ill newborns and initiate treatment for sepsis, also had a health education component that included nutrition in pregnancy. Two-thirds of the pregnant women in the intervention area received education in groups and $76 \%$ in individual home visits. No results of the impact of this component on the women's nutrition including use of iron/folic acid supplementation were reported.

Our findings highlight the need for studies, including randomised controlled trials, to examine the impact of different schedules of postnatal care services on neonatal mortality after carefully controlling for differential use of antenatal iron/folic acid before any benefits are ascribed to postnatal care intervention. This is not the case in studies ${ }^{16} 1834$ used to support the recommendation for use of postnatal care to reduce neonatal deaths in low-income and middle-income countries. A useful starting point would be to re-analyse these trials adjusting for the effect of use of iron/folic acid on risk of neonatal death. The assessment of the most effective schedule of postnatal visits is important to prevent unnecessarily increased workloads for health personnel in resource limited settings. The possibility of focusing postnatal visits only on the first day after delivery has been suggested, given the importance of the early days of life for an infant's survival. ${ }^{5}$

The increased risk of neonatal death associated with postnatal care services, especially for deaths on the first day of delivery can be explained by a referral bias since families are more likely to seek professional help when medical complications occur. These findings might also reflect the slow referral system in rural areas particularly if only extremely ill infants are referred to health professionals. This indicates the need to re-examine the recommendations of adding further postnatal care services in the first week of an infant's life prior to obtaining stronger evidence that additional investment in perinatal healthcare services will provide substantial benefit in improving neonatal survival.

Our analysis confirmed the benefit of iron/folic acid supplements against neonatal deaths, as previously reported in a cluster randomised trial from China ${ }^{13}$ and other observational epidemiological studies. ${ }^{11} 12142635$ It has been postulated that infants benefit from these supplements through an increase of gestation and birth weight, and reduction in preterm delivery as well as from the prevention of birth asphyxia. ${ }^{11} 1314 \mathrm{~A}$ recent observational study using IDHS data has reported that the protective effect of iron/folic acid supplements also extends through the first year of life although protection progressively decreased with increasing age. ${ }^{36}$ This study also found an increase in the number of iron/folic acid supplements consumed was associated with an increase in protection from child death. The long-term benefit of iron/folic acid supplements has also been reported in rural Nepal with reduced mortality among children less than 7 years with maternal supplementation. ${ }^{37}$

Although iron/folic acid supplements have been included in routine antenatal care, poor adherence to the daily supplementation regime remains a problem in Indonesia, as shown by the low percentage of pregnant women consuming all of the recommended 90 tablets. $^{9} 10$ Problems of supply and compliance ${ }^{38-40}$ should be addressed to increase uptake. In Indonesia, distribution of supplements is mainly through antenatal care services. As a consequence, women who underutilise antenatal care services, who are most likely to be in greatest need, do not receive supplements. Distribution needs to be improved to reach women in areas with limited access to care services. The traditional birth attendants, who are still highly utilised by women in remote areas, ${ }^{10} 41$ should be involved in public health programmes to distribute iron/folic acid in areas with limited access to health services.

\section{CONCLUSION}

In our analyses postnatal care provided no protection from neonatal death in Indonesia. This indicates the need to revisit the current priority given to postnatal care as a tool for reducing neonatal deaths and the recommendation to add visits to postnatal care schedule. Our findings highlight the important role of iron/folic acid supplementation for reducing the risk of neonatal death and the need for more investments in this intervention to accelerate reductions in neonatal mortality. Our findings about the relative impact of postnatal and antenatal iron/folic acid supplements, on neonatal survival are important for planning interventions to reduce newborn deaths in Indonesia and other low-income and middle-income countries. Research is needed to compare the benefits of early and extended use of iron/ folic acid with different timing and frequency of 
postnatal services to assess the relative benefit and effectiveness of these services.

Contributors Both authors participated in the design of the study, performed the data analysis and interpretation, and prepared and reviewed the manuscript. Both authors approved the final version of the manuscript to be published.

Competing interest None.

Provenance and peer review Not commissioned; externally peer reviewed.

Data sharing statement Data used in this study are available at the Measure DHS website (http://www.measuredhs.com/data/available-datasets.cfm).

\section{REFERENCES}

1. Rajaratnam JK, Marcus JR, Flaxman AD, et al. Neonatal, postneonatal, childhood, and under-5 mortality for 187 countries, 1970-2010: a systematic analysis of progress towards Millennium Development Goal 4. Lancet 2010;375:1988-2008.

2. Lawn JE, Cousens S, Zupan J, et al. 4 million neonatal deaths: when? Where? Why? Lancet 2005;365:891-900.

3. Lawn J, Kerber K, Enweronu-Laryea C, et al. Newborn survival in low resource settings-are we delivering? BJOG 2009;116:49-59.

4. United Nations. Road map towards the implementation of the United Nations Millennium Declaration: report of the Secretary-General. New York: United Nations, 2001:1-58.

5. Nair N, Tripathy P, Prost A, et al. Improving newborn survival in low-income countries: community-based approaches and lessons from South Asia. PLoS Med 2010;7:e1000246.

6. World Health Organization. Neonatal and perinatal mortality: country, regional and global estimates. Geneva: World Health Organization, 2006.

7. Chen X-K, Wen SW, Yang Q, et al. Adequacy of prenatal care and neonatal mortality in infants born to mothers with and without antenatal high-risk conditions. Aust N Z J Obstetr Gynaecol 2007:47:122-7.

8. Raatikainen K, Heiskanen N, Heinonen S. Under-attending free antenatal care is associated with adverse pregnancy outcomes. BMC Public Health 2007;7:268.

9. Ministry of Health Republic of Indonesia. Indonesia Health Profile 2008. Jakarta: Ministry of Health Republic of Indonesia, 2009.

10. Badan Pusat Statistik-Statistics Indonesia (BPS), National Family Planning Coordinating Board, Ministry of Health, et al. Indonesia Demographic and Health Survey 2007. Calverton, Maryland: BPS and ORC Macro, 2008

11. Cogswell ME, Parvanta I, Ickes $\mathrm{L}$, et al. Iron supplementation during pregnancy, anemia, and birth weight: a randomized controlled trial. Am J Clin Nutr 2003;78:773-81.

12. Pena-Rosas JP, Viteri FE. Effects of routine oral iron supplementation with or without folic acid for women during pregnancy. Cochrane Database Syst Rev 2006;(3):CD004736.

13. Zeng L, Dibley MJ, Cheng $Y$, et al. Impact of micronutrient supplementation during pregnancy on birth weight, duration of gestation and perinatal mortality in rural western China: double-blind cluster randomised controlled trial. BMJ 2008;337:a2522.

14. Siega-Riz AM, Hartzema AG, Turnbull C, et al. The effects of prophylactic iron given in prenatal supplements on iron status and birth outcomes: a randomized controlled trial. Am J Obstetr Gynecol 2006;194:512-19.

15. Bang AT, Bang RA, Baitule SB, et al. Effect of home-based neonatal care and management of sepsis on neonatal mortality: field trial in rural India. Lancet 1999;354:1955-61.

16. Baqui $\mathrm{AH}, \mathrm{El}-$ Arifeen $\mathrm{S}$, Darmstadt $\mathrm{GL}$, et al. Effect of community-based newborn-care intervention package implemented through two service-delivery strategies in Sylhet district, Bangladesh: a cluster-randomised controlled trial. Lancet 2008;371:1936-44.

17. Kumar V, Mohanty S, Kumar A, et al. Effect of community-based behaviour change management on neonatal mortality in Shivgarh, Uttar Pradesh, India: a cluster-randomised controlled trial. Lancet 2008;372:1151-62.

18. Baqui $\mathrm{AH}$, Ahmed $\mathrm{S}$, El Arifeen $\mathrm{S}$, et al. Effect of timing of first postnatal care home visit on neonatal mortality in Bangladesh: a observational cohort study. BMJ 2009;339:b2826.
19. Bhutta ZA, Memon ZA, Soofi S, et al. Implementing community-based perinatal care: results from a pilot study in rural Pakistan. Bull World Health Organ 2008;86:452-9.

20. World Health Organization, UNICEF. WHO/UNICEF Joint Statement home visits for the newborn child: a strategy to improve survival. Switzerland: World Health Organization, 2009.

21. Kementerian Kesehatan RI. Buku Saku Pelayanan Kesehatan Neonatal Esensial: Pedoman Teknis Pelayanan Kesehatan Dasar (Pocket Book of Essential Neonatal Health Care Services: Technical Guidlines of Basic Health Care Serivices). Jakarta, Indonesia: Kementerian Kesehatan RI, 2010.

22. Macro International Inc. Measure DHS: demographic and Health Surveys. Calverton, MD: ICF Macro, 2009.

23. Macro International Inc. Sampling manual. DHS-III Basic Documentation No. 6. Calverton, MD, 1996.

24. Mosley WH, Chen LC. An analytical framework for the study of child survival in developing countries. Popul Dev Rev 1984;10:25-45.

25. Filmer D, Pritchett LH. Estimating wealth effects without expenditure data-or tears: an application to educational enrollments in states of India. Demography 2001;38:115-32.

26. Titaley CR, Dibley MJ, Roberts CL, et al. Iron and folic acid supplements and reduced early neonatal deaths in Indonesia. Bull World Health Organ 2010;88:500-8.

27. Victora CG, Huttly SR, Fuchs SC, et al. The role of conceptual frameworks in epidemiological analysis: a hierarchical approach. Int J Epidemiol 1997;26:224-7.

28. Badan Pusat Statistik-Statistics Indonesia (BPS), National Family Planning Coordinating Board, Ministry of Health, et al. Indonesia demographic and health survey 2002-2003. Calverton, MD: BPS and ORC Macro, 2003

29. Hill K, Choi Y. Neonatal mortality in the developing world. Demogr Res 2006;14:429-52.

30. Mahy M. DHS Comparative Reports No 4: Childhood mortality in the developing world: a review evidence from the Demographic and Health Surveys. Calverton, MD: ORC Macro, 2003:68.

31. Hall S. Neonatal mortality in developing countries: what can we learn from DHS data? Applications \& policy working paper A05/02 Southampton, UK: Statistical Sciences Research Institute, 2005.

32. World Health Organization, Unicef. Joint Statement: iron supplementation of young children in regions where malaria transmission is intense and infectious disease highly prevalent Geneva: World Health Organization, 2006.

33. Darmstadt GL, Choi Y, Arifeen SE, et al. Evaluation of a cluster-randomized controlled trial of a package of community-based maternal and newborn interventions in Mirzapur, Bangladesh. PLoS One 2010;5:e9696.

34. Manandhar DS, Osrin D, Shrestha BP, et al. Effect of a participatory intervention with women's groups on birth outcomes in Nepal: cluster-randomised controlled trial. Lancet 2004;364:970-9.

35. Titaley CR, Dibley MJ, Roberts CL, et al. Combined iron/folic acid supplements and malaria prophylaxis reduce neonatal mortality in 19 sub-Saharan African countries. Am J Clin Nutr 2010;92:235-43.

36. Dibley M, Titaley C, Agho K, et al. Iron and folic acid supplements in pregnancy improves child survival in Indonesia. Am J Clin Nutr 2012;95:220-30.

37. Christian $\mathrm{P}$, Stewart $\mathrm{CP}$, LeClerq SC, et al. Antenatal and postnatal iron supplementation and childhood mortality in rural Nepal: a prospective follow-up in a randomized, controlled community trial. Am J Epidemiol 2009;170:1127-36.

38. Galloway R, McGuire J. Determinants of compliance with iron supplementation: supplies, side effects, or psychology? Soc Sci Med 1994:39:381-90.

39. Titaley CR, Hunter CL, Heywood P, et al. Why don't some women attend antenatal and postnatal care services? A qualitative study of community members' perspectives in Garut, Sukabumi and Ciamis districts of West Java Province, Indonesia. BMC Pregnancy Childbirth 2010;10:61

40. Galloway R, Dusch E, Elder L, et al. Women's perceptions of iron deficiency and anemia prevention and control in eight developing countries. Soc Sci Med 2002;55:529-44.

41. Titaley CR, Hunter CL, Dibley MJ, et al. Why do some women still prefer traditional birth attendants and home delivery? A qualitative study on delivery care services in West Java Province, Indonesia. BMC Pregnancy Childbirth 2010;10:43. 